\title{
Performance appraisal of SHASTA's complementary investment company's portfolio management
}

\author{
Ali Saeedi ${ }^{\mathrm{a}}$ and Robabeh Bahramian ${ }^{\mathrm{b}^{*}}$
}

${ }^{a}$ Assist. Prof. \& Faculty Member, Department of Accounting, School of Management and Human Sciences, Tehran North Branch, Islamic Azad University (IAU), Tehran, Iran

${ }^{b}$ M.Sc. Student, Department of Management, School of Management and Human Sciences, Tehran North Branch, Islamic Azad University (IAU), Tehran, Iran and Expert of Social Security Organization

\section{H R O N I C L E}

Article history:

Received May 9, 2013

Received in revised format

30 June 2013

Accepted 27 July 2013

Available online

July 272013

Keywords:

Performance Appraisal

Tehran Stock Exchange

SHASTA

\begin{abstract}
A B S T R A C T
This paper presents an empirical investigation to measure the performance of holding company compared with the performance of market using Sharp ratio over the period of 2008-2011. SHASTA is one of the biggest holding firms in Iran, owned by social security organization, and has some subsidiary firms. The study measures the risk of holding firm and market performance firms listed on Tehran Stock Exchange using the Sharp ratio. To compare the performance of holding versus subsidiary firms as well as the market, the study first performs normality test on the data. Statistical data for the performance of holding company is not normally distributed but all subsidiary data are normally distributed. Therefore, the study uses non-parametric test to measure the performance for holding company and parametric test is employed to measure the performance of other firms. The result of our investigation indicates that there was no difference between the performance of holding firm and market performance.
\end{abstract}

\section{Introduction}

Measuring the performances of financial firms has always been a major concern among investors in different markets (Amenc et al., 2003; Motamen-Samadian, 2005; Fabozzi, 2007; Reilly \& Brown, 2011). Arugaslan et al. (2008) evaluated the risk-adjusted performance of the largest US-based equity mutual funds based on rigorous analysis grounded in modern portfolio theory and explained the results in a manner which was comprehensible to a lay investor. They concluded that the funds with the highest returns could lose their attractiveness once the degree of risk had been factored into the

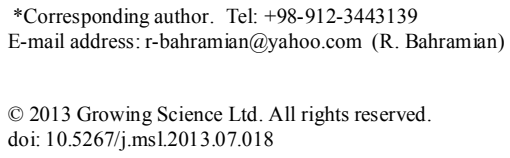


analysis. They also reported that, some funds could look very attractive once their low risk is factored into their performance.

van Hest and De Waegenaere (2007) presented optimal robust and consistent active implementation of a pension fund's benchmark investment strategy. They assumed that the benchmark strategy was given, and determined a model for its optimal active implementation, which involves a number of investment managers. They presented a mean-variance approach to detect, for each investment manager, the optimal budget as well as the fraction of that budget implemented for deviations from the benchmark. The emphasis was on robustness of the optimal allocation with respect to parameter misestimation, and on consistency in terms of risk-return preferences between active implementation and benchmark investment strategy.

Pendaraki et al. (2005) proposed an integrated methodological framework for the evaluation of mutual funds (MF) performance based on the combination of discrete and continuous multicriteria decision aid (MCDA) methods for MFs selection and composition. Plantinga et al. (2001) investigated the impact of downside risk on risk-adjusted performance of mutual funds in the Euronext markets. Engstrom et al. (2002) obtained new measures of the value of active portfolio management by forming replicating portfolios.

According to Arshanapalli et al. (2007), during the past few years, there have been considerable attention to devising market-timing strategies as potential value-enhancement tools. The success of such active or tactical asset allocation strategies normally depends on their capability to capture either inefficiencies, to the extent that they exist, or disequilibria associated with changes in the investor opportunity set. Much of the equity-style timing literature has concentrated on the shifting between pairs of risky assets or between one risky and one riskless asset class, based on a binomial approach.

Arshanapalli et al. (2007) developed a multinomial timing model based on macroeconomic and fundamental public information based on Frank Russell large-cap and small-cap style indexes. They modeled four various market segments, simultaneously and reported that active multi-style rotation strategies could be devised that outperform the best performing buy-and-hold portfolio.

Gharakhani and Sadjadi (2013) presented a fuzzy compromise programming approach for the BlackLitterman portfolio selection model. They examined advanced optimization method for portfolio problem introduced by Black and Litterman to investigate the shortcomings of Markowitz standard Mean-Variance optimization. Black and Litterman proposes a new approach to estimate asset return as a way to incorporate the investor's views into asset pricing process. Since the investor's view about future asset return is always subjective and imprecise, we may represent it by using fuzzy numbers and the resulting model was multi-objective linear programming. Therefore, the proposed model was analyzed through fuzzy compromise programming approach based on appropriate membership function. Zhu et al. (2011) solved portfolio optimization based on the implementation of particle swarm optimization.

Khodaei Valahzaghard et al. (2012) investigated the effects of economic factors not affected by intentional behavior of customers in Iranian banking system including all public and private banks. They concluded that the credit risk in the banking system in Iran under the influence of variables was not mentioned. In addition, positive and significant relationship between stock index and credit risk in the banking system in Iran has increased by Weber in this index increases and reducing credit risk is reduced.

Akuzawa and Nishiyama (2013) proposed a criterion for portfolio selection, implied excess Sharpe ratio. The implied excess Sharpe ratio was applied as an excess Sharpe ratio where investors could expect to enjoy from portfolios that include options and is a useful ex ante indicator. To examine the 
benefit of the concept, they built an investment strategy that automatically chooses from multiple candidate portfolios and they are made up of combinations of Nikkei futures and Nikkei listed options the portfolio with the largest implied excess Sharpe ratio.

\section{The proposed model}

The proposed study of this paper presents an investigation to measure the performance of holding company compared with the performance of market using Sharp ratio over the period of 2008-2011. SHASTA is one of the biggest holding firms in Iran, owned by social security organization, and has some subsidiary firms. The study measures the risk of holding firm and market performance firms listed on Tehran Stock Exchange using the Sharp ratio (Sharpe, 1992) based on the following relationship,

$$
R V A R=\frac{r_{p}-r_{f}}{\sigma_{p}},
$$

where $r_{p}, r_{f}$ and $\sigma_{p}$ are return of portfolio, risk free assets and standard deviation of portfolio, respectively. In addition, $R V A R$ is the sharp ratio used for the proposed study of this paper. Table 1 summarizes the results of $r_{p}, r_{f}$ and $R V A R$ for the proposed study of this paper.

Table 1

The summary of the proposed study

\begin{tabular}{lcc}
\hline Group & Market & Sub-group firms \\
\hline Average standard deviation & 0.0137 & 3.3112 \\
The unadjusted average market & 0.0203 & 9.5214 \\
RVAR & 0.43 & 3.66 \\
\hline
\end{tabular}

Table 2

The summary of market performance versus subsideries

\begin{tabular}{ccccc}
\hline & \multicolumn{2}{c}{ Adjusted return } & \multicolumn{2}{c}{ Unadjusted sharp ratio } \\
Group & Min & Max & Min & Max \\
\hline Market & -0.11 & 0.18 & -16.35 & 31.26 \\
SHASTA subsidiaries & -55.39 & 69.26 & -22.62 & 34.46 \\
\hline
\end{tabular}

As we can observe from the results of Table 2, SHASTA subsidiary firms have performed much wider range of performance and sharp ratio compared with market performance. In other words, while SHASTA maintains a minimum return of $-55.39 \%$, the minimum loss was reported only -0.11 . Similar pattern is considered on the information associated with sharp ratio.

The first step to examine the hypothesis of this survey is to find out whether the gathered data are normally distributed or not. We have implemented four tests including Lilliefors (D), Cramer-von Mises (W2), Watson (U2) and Anderson-Darling (A2) and the results for on market data are $>0.1$, $0.5589,0.6534$ and 0.5084 , respectively. Since all information are greater than 0.05 we can conclude that the market data are normally distributed. In addition, we have repeated the same tests on the information of SHASTA holding group and the results of four mentioned tests are $>0.1,0.4744$, 0.4349 and 0.6424 , respectively. Therefore, we can conclude that the raw data gathered on SHASTA holding group are normally distributed. Next, we perform some statistical tests to find out whether two groups of information maintain equal variance or not. Table 3 shows details of our survey, 
Table 3

Testing equality of variances between market and holding group

\begin{tabular}{lccc}
\hline Method & $\mathrm{df}$ & value & Probability \\
\hline F-test & $(51,51)$ & 192588.4 & 0.0000 \\
Siegel-Tukey & & 8.318290 & 0.0000 \\
Bartlett & 1 & 544.5447 & 0.0000 \\
Levene & $(1,102)$ & 100.5788 & 0.0000 \\
Brown-Forsythe & $(1,102)$ & 87.00439 & 0.0000 \\
\hline
\end{tabular}

The results of all five tests including F-test, Siegel-Tukey, Sartlett, Levene and Brown-Forsythe are statistically significant, which means two groups of variable maintain difference variances. In order to compare the mean of two groups we have used Satterthwaite-Welch t-test and Welch F-test and the results are 0.0182 for both. This means two groups have different means.

\section{The results}

In order to verify whether there is any difference between the performance of two firms in terms of mean Sharp ratio, we have performed the investigation in terms of years of 2008, 2009, 2010 and 2011 and in each year, we evaluate the following hypothesis,

$\begin{cases}H_{0}: & R_{V A R_{p}} \leq R V A R_{M} \\ H_{1}: & \operatorname{RVAR}_{p}>R V A R_{M}\end{cases}$

where $R V A R_{p}$ and $R V A R_{M}$ are average sharp ratios of SHASTA portfolio and market, respectively. Again, We have implemented four tests including Lilliefors (D), Cramer-von Mises (W2), Watson (U2) and Anderson-Darling (A2) for SHASTA subsidiaries firms and the results for market data are $>0.1,0.4433,0.4643$ and 0.5085 , respectively. Since all information are greater than 0.05 we can conclude that the market data are normally distributed. However, the results of these mentioned tests on market data do not confirm that they are normally distributed we examine the medians between different series. Table 4 summarizes the results of equality of medians between different series of data.

Table 4

The summary of statistical tests

\begin{tabular}{llll}
\hline Method & df & Value & Probability \\
\hline Wilcoxon/Mann-Whitney & & 1.745569 & 0.0809 \\
Wilcoxon/Mann-Whitney (tie-sdj) & & 1.745569 & 0.0809 \\
Med. Chi-Square & 1 & 2.461538 & 0.1167 \\
Adj. Med Chi-Square & 1 & 1.884615 & 0.1698 \\
Kruskal-Wallis & 1 & 3.058369 & 0.0803 \\
Kruskal-Wallis (tie-adj) & 1 & 3.058369 & 0.0803 \\
Van der Waerden & 1 & 2.934181 & 0.0867 \\
\hline
\end{tabular}

As we can observe from the results of different statistical tests, none of the statistical observations is meaningful when the level of significance is five percent. Table 5 demonstrates the results of our survey in terms of comparing the median and variances.

The results of Table 5 demonstrate that when we have compared the performance of unadjusted return of market with unadjusted performance of SHASTA group, the SHASTA group has demonstrated higher performance. 
Table 5

The summary of the results of our survey

\begin{tabular}{lcccc}
\hline & \multicolumn{2}{c}{ Unadjusted return based on risk } & \multicolumn{2}{c}{ Adjusted Sharp ratio based on risk } \\
\hline Test & Market & SHASTA & Market & SHASTA \\
Normality & Normal & Normal & Not-normal & Normal \\
Median equity & - & - & smaller & Larger \\
Variance equity & Not-equal & Not-equal & Not-equal & Not-equal \\
\hline Mean equity & smaller & Bigger & Somehow smaller & Somehow larger \\
\hline
\end{tabular}

\section{Discussion and conclusion}

In this paper, we have tried to compare the performance of SHASTA group, the biggest holding firm owned by Iranian Social security, with market performance over the period 2008-2011. The study used Sharp ratio for comparing the performance of SHASTA group versus market. Our study shows that when we have compared the performance of unadjusted return of market with unadjusted performance of SHASTA group, the SHASTA group demonstrated higher performance. In addition, when we compared the performance of adjusted performance of SHASTA with market, SHASTA did slightly better than market. In other words, when we do not take into account the risk ratio, SHASTA did better than market in terms of performance. However, when we take into account the risk ratio, there is not much difference between the performance of SHASTA and market return. The results of our findings are consistent with findings of Arugaslan et al. (2008).

In summary, we can conclude that when we plan to invest, we need to have a closer look at risk/reward ratios. There is no doubt that firms with higher risk leverage may provide higher return but when we compare these two factors, we may not necessary jump into high risk assets.

\section{Acknowledgment}

The authors would like to thank the anonymous referees for constructive comments on earlier version of this paper.

\section{References}

Akuzawa, T., \& Nishiyama, Y. (2013). Implied Sharpe ratios of portfolios with options: Application to Nikkei futures and listed options. The North American Journal of Economics and Finance, 25, 335-357.

Amenc, N., Malaise, P., Martellini, L., \& Sfeir, D. (2003). Tactical style allocation-A new form of market neutral strategy. The Journal of Alternative Investments, 6(1), 8-22.

Arshanapalli, B. G., Switzer, L. N., \& Panju, K. (2007). Equity-style timing: A multi-style rotation model for the Russell large-cap and small-cap growth and value style indexes. Journal of Asset Management, 8(1), 9-23.

Arugaslan, O., Edwards, E., \& Samant, A. (2008). Evaluating large US-based equity mutual funds using risk-adjusted performance measures. International Journal of Commerce and Management, 17(1/2), 6-24.

Gharakhani, M \& Sadjadi, S. (2013). A fuzzy compromise programming approach for the BlackLitterman portfolio selection model. Decision Science Letters, 2(1), 11-22.

Engstrom, S. (2002). Does active portfolio management create value? An evaluation of fund managers' decisions. An Evaluation of Fund Managers' Decisions (January 28, 2004).

Fabozzi, F. J. (2007). Bond Markets: Analysis And Strategies, 5/E. Pearson Education India.

van Hest, T., \& De Waegenaere, A. (2007). Optimal robust and consistent active implementation of a pension fund's benchmark investment strategy. Journal of Asset Management, 8(3), 176-187. 
Khodaei Valahzaghard, M., Kashefi, M., Alikhani, A \& Hosseini, S. (2012). The effect of macroeconomic factors on credit risk in the banking system of Iran. Management Science Letters, 2(5), 1747-1754.

Motamen-Samadian, S. (Ed.). (2005). Risk management in emerging markets. Palgrave Macmillan.

Pendaraki, K., Zopounidis, C., \& Doumpos, M. (2005). On the construction of mutual fund portfolios: A multicriteria methodology and an application to the Greek market of equity mutual funds. European Journal of Operational Research, 163(2), 462-481.

Plantinga, A., van der Meer, R., \& Sortino, F. (2001). The impact of downside risk on risk-adjusted performance of mutual funds in the Euronext markets. Geneva Papers on Risk and Insurance, 1-14.

Reilly, F. K., \& Brown, K. C. (2011). Investment analysis and portfolio management. CengageBrain. com.

Sharpe, W. F. (1992). Asset allocation: Management style and performance measurement. The Journal of Portfolio Management, 18(2), 7-19.

Zhu, H., Wang, Y., Wang, K., \& Chen, Y. (2011). Particle Swarm Optimization (PSO) for the constrained portfolio optimization problem. Expert Systems with Applications, 38(8), 10161-10169 